\title{
Cationic Peptides Harboring Antibiotic Capacity are Selective for Leishmania panamensis and Leishmania major
}

\author{
José Manuel Lozano ${ }^{1,2 *}$, Bernarda Soraya Cuadrado ${ }^{3}$, Gabriela Delgado ${ }^{4}$ and Manuel Elkin Patarroyo ${ }^{1,2}$ \\ 1 Universidad Nacional de Colombia, Bogotá, Colombia \\ ${ }^{2}$ Biocatalysis Department, Fundación Instituto de Inmunología de Colombia (FIDIC) / Universidad del Rosario, Bogotá, Colombia \\ ${ }^{3}$ Pharmacy Department, Science Faculty, Universidad de Cartagena, Cartagena, Colombia \\ ${ }^{4}$ Immunotoxicology Research Group, Pharmacy Department, Science Faculty, Universidad Nacional de Colombia, Bogotá, Colombia
}

\begin{abstract}
The fairly recent appearance of Leishmania resistance to currently-used therapy has led to the search for new therapeutic strategies. This work was thus aimed at evaluating the in vitro effect of 18 cationic synthetic antimicrobial peptides for antileishmanial and cytotoxic and haemolytic activity. The viability of murine (J774) and human (U937), peripheral blood monocytes, HeLa and HepG2 cells and $L$. (V) panamensis and $L$. (L) major promastigotes was then ascertained using the aforementioned peptides. All antimicrobial peptides were synthesised and each cell and parasite line was treated with different peptide concentrations. Melittin, bombinin, mastoparan 8 (MP-8), MP-X and dermaseptin-S1 reduced human and murine host cells' viability at greater concentrations than pentamidine isethionate, human peripheral blood and U937 monocytes being the most sensitive to peptide action. Melittin had a toxic effect on all the cells evaluated in this study and $L$. (L) major was more sensitive than $L$. (V) panamensis to peptide effect. As MP-8, bombinin, dermaseptin-S1 and tracheal antimicrobial peptide (TAP) were active against both parasite species, and tachyplesin 1 and polystes MA selectively so for $L$. ( $L$ ) major, they were selected as being promising as they had a $>1$ selectivity index (SI) and greater than $50 \mu \mathrm{g} / \mathrm{mL}$ haemolytic concentration (HC50), suggesting that they should continue to be studied in in vitro and in vivo infection assays as there have been no previous reports of MP-8, bombinin, TAP and Polystes MA activity regarding $L$. (V) panamensis and $L$. (L) major.
\end{abstract}

Keywords: Antimicrobial Peptide; Leishmaniasis; Leishmania ssp; Cytotoxicity; Microbial Resistance to Antibiotics

\section{Introduction}

Leishmaniasis covers a group of diseases characterised by their clinical and epidemiological diversity; it is caused by around 22 species of protozoa from the genus Leishmania, belonging to the family Trypanosomatidae. They are grouped into two subgenera: Leishmania (L), mainly in Afro-Eurasia, and Viannia (V) on the American continent. They are transmitted by a haematophagous insect's bite (most being zoonotic where carnivorous animals are concerned) and some rodents, acting as the main reservoirs [1,2].

The number of people becoming infected with leishmaniasis around the world exceeds 20 million each year, around two million new cases being reported annually; 1.5 million have cutaneous manifestations but only $20 \%$ of the cases are accurately accounted for. Mortality has been estimated at around 60,000 people per year (mainly associated with the visceral form) and almost 350 million people are at risk of contracting the disease [3].

Leishmaniasis is endemic in almost all of Colombia, around 10 million people being at risk in rural areas. Around $98 \%$ of such cases involve the cutaneous clinical form which is mainly caused by $\mathrm{L}$. Viannia panamensis; however, it is attributed to $L$. $(L)$ major and $L$. $(L)$ tropica [4] in the Old World (Europe, Asia and Africa).

Leishmaniasis leads to a 2.35 million disability-adjusted life years (DALY) burden of disease, 2.3\% of them occurring in the Americas. Both cutaneous and mucocutaneous manifestations deform and disfigure to such a degree that such patients may become sociallyisolated and their quality of life becomes significantly reduced as cutaneous leishmaniasis (CL) is not fatal [3].

The drugs usually used in treatment are hepatotoxic and cardiotoxic (i.e. pentavalent antimony salts, bis-amidines, pentamidine and amphotericin B), thereby leading to clinical resistance following a few weeks' treatment. The cost of treatment and the need for parenteral administration hampers treatment and leads to its failure. A lack of worldwide interest in investing in research and development regarding new drugs and the diversity of clinical manifestations, the parasite's species, difficulty in controlling vectors and reservoirs and a lack of an effective vaccine $[3,5]$ all make it imperative for a search to be made for therapeutic strategies for replacing or complementing existing ones.

Antimicrobial peptides are key effector molecules in an organism's innate immunity [6]; they are isolated from different sources [7], about 2,000 sequences having been reported to date. They share some chemical features; such families of active molecules represent the main mechanism of action regarding the plasmatic membrane causing direct destabilisation through pore formation on the target cell, followed by cell lysis. This is why their potential use is being studied as a therapeutic strategy in infectious diseases such as leishmaniasis so that target cells resistance in not induced due to their action on membrane phospholipids and an organism's difficulty in modifying its own structure. Positive properties may be found among this group of molecules exceeding the disadvantages involved in using currentlyavailable drugs for leishmaniasis.

*Corresponding author: José Manuel Lozano, Head of the Biocatalysis Department, Fundación Instituto de Inmunología de Colombia (FIDIC), Carrera 50 No. 26-20, ZIP Code 020304, Bogotá DC, Colombia, Tel: +57-1-481-5219; Fax: +57-1-481-5269; E-mail: jm_lozano@fidic.org.co/jmlozanom@unal.edu.co

Received December 09, 2013; Accepted January 09, 2014; Published January 15,2014

Citation: Lozano JM, Cuadrado BS, Delgado LG, Patarroyo ME (2014) Cationic Peptides Harboring Antibiotic Capacity are Selective for Leishmania panamensis and Leishmania major. J Microb Biochem Technol 6: 054-062. doi:10.4172/19485948.1000122

Copyright: (c) 2014 Lozano JM, et al. This is an open-access article distributed under the terms of the Creative Commons Attribution License, which permits unrestricted use, distribution, and reproduction in any medium, provided the original author and source are credited 
Peptide anti-leishmanial activity against promastigotes from the subgeneraLeishmaniahassofarinvolved testing dermaseptin, bombinin, magainin, cathelicidin, defensin, temporin, decoralin, Pr-2 and Pr-3 (protamine derivatives), a cathelicidin (bovine myeloid antimicrobial peptide-28 or BMAP-28) and two stereoisomers (D-BMAP-28 and RI-BMAP-28) [11] against $L$. (L) major [8-11]. Likewise, the following peptides have been evaluated against the subgenera Viannia: tachyplesin, magainin, clavanin, penadein, mytilinin against $L$. (V) braziliensis and dermaseptin and a DM1 analogue and Pr-2 and Pr-3 protamine derivatives against $L$. (V) panamensis [8,12-14]. A model of $L$. (V) panamensis infection of dendritic cells has recently been reported demonstrating potencial antileishmanial activity of andropin and cecropin. Relatively few studies have been published evaluating antimicrobial peptide activity against $L$. (V) panamensis that is why we decide to assess some antimicrobial peptides and their potential against leishmania strains in controlled tests.

This study was aimed at screening the in vitro antileishmanial activity of 18 synthetic antimicrobial peptides regarding extracellular forms of $L .(V)$ panamensis and $L .(L)$ major and the effect they induced in human and murine erythrocytes and cells, thereby leading to ascertaining promising peptides having selective activity against the target parasite.

\section{Materials and Methods}

\section{Bioinformatics and in silico molecular analyses}

The amino acid sequences of all antimicrobial peptides selected for this research were aligned against different homologous proteins, including other human and non-human leishmanial parasites, all reported in the NCBI database (http://www.ncbi.nlm.nih.gov/blast. cgi). Sequences were aligned using the TBLASTN tool and the ClustalW multiple sequence alignment method (www.personal.rhul.ac.uk/ ujba/110/bioinfo/clustalE.html). Also PDB stored coordinates for most antrimicrobial peptides were downloaded from the Protein data bank web site (http://www.rcsb.org/pdb/home/home.do) regarding peptides 3D structure determined either by NMR or X-ray crystallography and then those were molecularly modelled. Molecular models were obtained using Accelrys Inc. Viewer Lite 4.2 software (www.accelrys. com).

\section{Solid phase synthesis of cationic antimicrobial peptides}

Eighteen previously-reported natural antimicrobial peptides as well as a human endogenous MHC-II restricted peptide so-named CLIP (Class II-associated invariant chain peptide) which lack any antimicrobial property (control peptide), were selected and synthesized for this study in line with standard protocols. In brief, all molecules were manually synthesized through tert-butyloxycarbonyl (t-Boc)-based solid-phase peptide synthesis (SPPS), following a protocol first reported by Merrifield [15] and later modified for multiple peptide synthesis [16]. Solid supports of $0.4 \mathrm{meq} / \mathrm{g}$ and $0.7 \mathrm{meq} / \mathrm{g}$ methylbenzhydrilamine (MBHA) resin substitutions were used in agreement to each peptide length for producing an average of $100 \mathrm{mg}$ of each peptide product. A controlled step-wise synthesis was performed by systematically coupling each building block (amino acid) accordingly with designed sequences. Amino acids were $\mathrm{t}$-Boc protected at their $\mathrm{N}$-terminus and a low-high hydrogen fluoride (HF) concentration procedure for peptideresin cleavage was employed when finalizing all amino acid couplings for releasing the synthesised peptide and so obtaining all crude peptide products in an average of $70 \%$ in yield. Total coupling was checked by the Ninhydrin test and, repeating the coupling reaction when necessary to ensure right couplings. Coupling was allowed to proceed for one to two hours under constant shaking, followed by washes with $\mathrm{N}, \mathrm{N}$-dimethylformamide (DMF), isopropanol and dichloromethane. Standard solid phase peptide synthesis was carried out to introduce all required $\mathrm{t}$-Boc amino acids to the last $\mathrm{N}$-terminal residue. Protected peptide-resin batches were treated with trifluoroacetic acid (TFA) to release those amino acids' side-chain protectin groups and the product peptide was cleaved from the resin by treatment with low concentrations of anhydrous hydrogen fluoride (HF) containing $10 \%$ anisole at $0^{\circ} \mathrm{C}$ for $60 \mathrm{~min}$. After HF evaporation in an $\mathrm{N}_{2}$ stream, each peptide-resin product was washed with cold diethyl ether, then extracted with $5 \%$ acetic acid (HOAc) and lyophilized.

Peptide identity and purity were analysed by mass spectrometry matrix-assisted laser desorption/ionisation time-of-flight (MALDITOF) and reverse phase high resolution liquid chromatography (RP-HPLC), respectively. The secondary structure profile of every synthesised peptide was then identified by circular dichroism (CD) experiments [17].

An analytical RP-HPLC was run (Hitachi-Merck model L17400, Merck, Darmstadt, DE) using a silica analytical column (Vydac C-18) $(5 \mu \mathrm{m}, 4.5 \mathrm{~mm} \times 30 \mathrm{~cm})$. A Vydac C- 18 column was used in preparative RP-HPLC for $0 \%$ to $100 \% \mathrm{~B}$ gradient-lineal elution using the following solvent system: a) $\mathrm{H}_{2} \mathrm{O}, 0.05 \%$ trifluoroacetic acid (TFA), b) $\mathrm{CH}_{3} \mathrm{CN}$, $0.05 \% \mathrm{TFA}$ for $45 \mathrm{~min}$ (100 $\mathrm{min}$ for preparation) at $1.0 \mathrm{~mL} / \mathrm{min}$ flow speed $(4.5 \mathrm{~mL} / \mathrm{min}$ for preparation). The eluate was monitored on a UV-DAD detector at $220 \mathrm{~nm}$.

Mass spectra were recorded on a Bruker Protein TOF mass spectrometer (Billerica, MA) in reflectron mode. MALDI experiments involved TOF using a $337 \mathrm{~nm}$ long $\mathrm{N}_{2}$ radiant laser with 3-ns pulses. Acceleration voltage was $+17.5 \mathrm{kv}$ with $+20 \mathrm{kv}$ reflectron voltages; all spectra were obtained by a series of 10 laser pulses to ensure comparable conditions and that laser intensity was the minimum possible for each measurement. a-cyano-4-hydroxycinamic acid (CCA) (Sigma Chemical Co., Saint Louis, MO) was used as matrix in this work; it was prepared with a saturated solution in $1 \mathrm{~mL}$ TA ( $40 \%$ acetonitrile in $0.1 \%$ trifluoroacetic acid).

The samples were dissolved in TA to obtain a $100 \mathrm{pmol} / \mathrm{pL}$ concentration and prepared for MALDI-TOF analysis by diluting the sample in the matrix-saturated solution at $10 \mathrm{pmol} / \mu \mathrm{L}$ concentration. $0.5 \mu \mathrm{L}$ aliquots of the matrix-sample mixture were placed on a plate to become air-dried for later analysis (i.e. identifying secondary structure tendency by circular dichroism).

The peptides having greater than $95 \%$ purity which were included in the study were apamin, andropin, tracheal antimicrobial peptide (TAP), polystes MA (MA), mastoparan 8 (MP-8), mastoparan 17 (MP-17), mastoparan X (MP-X), a protamine derivative or $\mathrm{Pr}-2$, mangainin-1, dermaseptin S1, melittin, bombinin, tachyplesin I and cecropins A, B and P1. All were 10- to 40-amino acid long, had less than $3 \mathrm{kDa}$ molecular weight; seven of them had previouslydescribed antileishmanial activity and nine lacked reports concerning their activity (Table 1). A lineal non-related peptide from the major histocompatibility complex class II-associated invariant chain peptide (or CLIP) sequence was included as negative control (i.e. lacking a-helix structure), being non-microbicidal or immunogenic and naturally produced by cells (Table 1 ).

Lyophilised antimicrobial peptides were suspended in 3\% (v/v) dimethylsulfoxide or DMSO (Panreac, Barcelona, Spain) and $1 \mathrm{mg} /$ $\mathrm{mL}$ concentration (stock solution) incomplete Roswell Park Memorial Institute-1640 (RPMI-1640) culture medium (Gibco, Scotland, UK) and stored until use at $-20^{\circ} \mathrm{C}$. 
Citation: Lozano JM, Cuadrado BS, Delgado LG, Patarroyo ME (2014) Cationic Peptides Harboring Antibiotic Capacity are Selective for Leishmania panamensis and Leishmania major. J Microb Biochem Technol 6: 054-062. doi:10.4172/1948-5948.1000122

\begin{tabular}{|c|c|c|c|c|c|}
\hline $\begin{array}{l}\text { L. (V.) panamensis } \\
\text { Antimicrobial peptide }\end{array}$ & Sequence & $\begin{array}{l}\text { Molecular } \\
\text { weight (Da) }\end{array}$ & Natural source & $\begin{array}{l}\text { Secondary } \\
\text { structure tendency }\end{array}$ & $\begin{array}{l}\text { Antileishmanial } \\
\text { activity }\end{array}$ \\
\hline Manganin-1 & GIGKFLHSAGKFGKAFVGEIMKS & 2410.4 & Xenopus laevis & $\beta$-sheet & $\begin{array}{l}\text { Manganin-2: L. (L.) } \\
\text { donovani [14] and } \\
\text { analogues: L. (V.) } \\
\text { braziliensis [13] }\end{array}$ \\
\hline Dermaseptin S1 & ALWKTMLKKLGTMALHAGKAALGAAADTISQGTQ & 3437.6 & Phyllomedusa bicolor & a-helix & $\begin{array}{l}\text { L.(L.) amazonensis } \\
{[31] \text { L. (V.) }} \\
\text { panamensis and L.(L.) } \\
\text { major [18] }\end{array}$ \\
\hline Bombinin & GIGGALLSAGKSALKGLAKGLAEHFAN & 2904.4 & Bombina maxima & a-helix & $\begin{array}{l}\text { L. (L.) donovani } \\
{[10,12]}\end{array}$ \\
\hline Andropin & VFIDILDKVENAIHNAAQVGIGFAKPFEKLINPK & 3732.8 & $\begin{array}{l}\text { Drosophila } \\
\text { melanogaster }\end{array}$ & a-helix & L. (V.) panamensis[8] \\
\hline TAP & NPVSCVRNKGICVPIRCPGSMKQIGTCVGRAVKCCRKK & 4073.6 & Bos taurus & a-helix & Not described \\
\hline Cecropin B & KWKVFKKIEKNGRNIRNGIVKAGPAIAVLGEAKAL & 3818.3 & Hyalophour cecropia & a-helix & Not described \\
\hline Cecropin P1 & SWLSKTAKKLENSAKKRISEGIAIAIQGGPR & 3321.4 & Ascaris suum & a-helix & $\begin{array}{l}\text { No activity in L. (V.) } \\
\text { panamensis and L.(L.) } \\
\text { major [8] }\end{array}$ \\
\hline Cecropin A & KWKLFKKIEKVGQNIRDGIIKAGPAVAVVGQATQIAK & 4003.8 & Hyalophour cecropia & a-helix & L. (V.) panamensis [8] \\
\hline Polystes MA & VDWKKIGQHILSVL & 1618.1 & Polystes jadwigae & Non-structured & Not described \\
\hline Melittin & GIGAVLKVLTTGLPALISWIKRKRQQ & 2829.7 & $\begin{array}{l}\text { Polystes sp. HQL- } \\
2001\end{array}$ & a-helix & L. (L.) major [8] \\
\hline Tachyplesin I & KWCFRVCYRGICYRRCR & 2251.2 & $\begin{array}{l}\text { Tachypleus } \\
\text { tridentatus }\end{array}$ & $\beta$-sheet & $\begin{array}{l}\text { L.(V.) braziliensis, } \\
\text { guyanensis and } \\
\text { panamensis [13] }\end{array}$ \\
\hline Apamin & CNCKPEPALCARRCQQH & 2014.5 & Apis cerana cerana & a-helix & Not described \\
\hline $\operatorname{Pr}-2$ & VRRRRRPR & 1133.4 & $\begin{array}{l}\text { Oncorhynchus } \\
\text { mykiss gairdneri }\end{array}$ & a-helix & L. (V.) panamensis [8] \\
\hline MP-8 & INLKALAALAKRLL & 1490.3 & Vespa magnifica & a-helix & Not described \\
\hline MP- 17 & INLKAKAALAKKLL & 1477.3 & Vespa magnífica & a-helix & Not described \\
\hline MP-X & INWKGIAAMAKKLL & 1539.3 & $\begin{array}{l}\text { Vespa simillina } \\
\text { xanyhophera }\end{array}$ & a-helix & Not described \\
\hline CLIP & LPKPPKPVSKMRMATPLLMQALPM & 2674.5 & $\begin{array}{l}\text { MHC class II CD74 } \\
\text { (invariant chain) } \\
\text { molecule [Homo } \\
\text { sapiens] }\end{array}$ & $\begin{array}{l}\text { polyprolin-II (PPII) } \\
\text { helix }\end{array}$ & $\begin{array}{l}\text { Endogenous peptide } \\
\text { No antimicrobial or } \\
\text { cytotoxic activity }\end{array}$ \\
\hline
\end{tabular}

Table 1: Antimicrobial peptides' physical and antimicrobial profiles CLIP was used as a non-related peptide.

\section{Circular dichroism experiments}

Circular dichroism (CD) assays were performed at room temperature on nitrogen-flushed cells using a Jasco J-810 spectropolarimeter (Madrid, Spain). Spectra were recorded within a 190-250 nm wavelength interval using a 1-mm path length rectangular quartz cell. Each spectrum was obtained from averaging three scans taken at a scan rate of $20 \mathrm{~nm} / \mathrm{min}$ with $1-\mathrm{nm}$ spectral bandwidth and corrected for baseline deviation using Jasco software. CD profile of each molecule was obtained by dissolving lyophilized purified peptides in $0-30 \%$ aqueous 2,2,2-trifluoroethanol (TFE) in a final volume of 500 $\mathrm{mL}$. A typical $0.2 \mathrm{mM}$ peptide concentration in TFE-water mixture is stabilized but does not induce secondary structure in peptides, as described elsewhere [18].

\section{Parasite culturing}

Leishmania (V)panamensis (MHOM/PA/71/LS94) and Leishmania (L) major Friedlin 6 clone (MHOM/IL/80/Friedlin) promastigotes cultured at $27^{\circ} \mathrm{C}$ in complete RPMI 1640 medium: RPMI medium (Gibco, Scotland, UK) buffered with $2 \mathrm{mM} \mathrm{NaHCO}_{3}, \mathrm{pH} 7.2$ and supplemented with $5 \%(\mathrm{v} / \mathrm{v})$ fetal calf serum (FCS) (Microgen, Bogotá, CO), 2 mM L-glutamine (Gibco, Grand Island, NY, USA), 100 U/mL penicillin and $100 \mathrm{mg} / \mathrm{mL}$ streptomycin (complete medium) were used for the assays.

\section{Cells lines}

Human (U937) and murine (J774) monocyte/macrophage cell lines, human HepG2 lines (representing hepatocytes) [19] and HeLa (representing immortal cells) (ATCC, Rockville, USA), peripheral blood monocytes from healthy donors and fresh $\mathrm{O} \mathrm{Rh}+$ red blood cells (RBC) were used for evaluating the peptides' antibiotic effect. Monocytes/macrophages and HepG2 and HeLa cells were cultured in complete RPMI- 1640 medium at $37^{\circ} \mathrm{C}$ with $95 \%$ humidity and $5 \% \mathrm{CO}_{2}$ until forming a monolayer at $80 \%$ confluence.

Human peripheral blood monocytes (with Buffy coat or white cell layer) and erythrocytes were obtained from healthy donors using blood bags (Marly Clínic Blood Bank, Bogotá, Colombia), complying with Colombian Ministry of Social Protection resolution $8430 / 1993$ concerning research involving human tissue. The samples were processed using a previously-described technique, with some modifications [20]. The monocytes were separated by Ficoll-Paque 1077 density gradient (Lympho separation medium, MP Biomedicals LLC, Ohio, USA) and spun at $1.077 \mathrm{x} g$ for 30 minutes; the cells were then washed and suspended in incomplete RPMI medium and 1:1 saline solution supplemented with $5 \%(\mathrm{v} / \mathrm{v})$ foetal calf serum (FCS) and sown on $150 \mathrm{~cm}^{2}$ plastic Petri dishes (NalgeNunc International Rochester, New York, USA). They were then incubated at $37^{\circ} \mathrm{C}$ with $5 \% \mathrm{CO}_{2}$ for two hours to allow them to adhere to the plates. The adhered cells were then separated, their number and percentage viability (greater than $90 \%$ ) determined by $0.4 \%$ Trypan blue dye exclusion assay (Gibco, NY) and then sown on flat-bottomed 96-well plates (TPP, Techno Plastic Products AG, Trasadingen, $\mathrm{CH}$ ) at $2 \times 10^{5}$ cells $/ \mathrm{mL}$ complete RPMI1640 concentration, until being used in the respective assays. 


\section{Antimicrobial peptide effect on the cells}

The fluorometric resazurin reduction test was used, following a previously-described methodology [21]; this led to identifying peptides which could cause a possibly harmful effect on eukaryotic cells, particularly on potential host cells. All were different to the Leishmania parasite (safety and efficacy criteria). Four series of peptide dilutions in duplicate and two antileishmanial drugs (paromomycin sulphate and pentamidine isethionate) were added to the cell cultures, including controls for the diluent used dimethylsulfoxide (DMSO) and peptidefree cells. Resazurin reduction to rezorufin (fluorescent compound) was detected on Tecan Genios Spectra Fluor Plus equipment (Tecan Austria GmbH, Untersbergstrasse Grödig, Salzburg, Austria), at 535 $\mathrm{nm}$ excitation and $590 \mathrm{~nm}$ emission wavelength using Magellan RFU-4 software (Tecan, UK). Viability was calculated then estimated.

\section{Haemolytic activity of antimicrobial peptides}

Human O+ RBC from heparinised blood obtained by venopuncture was studied as it was considered part of the safety criteria. The RBC were diluted at $2 \%$ haematocrite and incubated with $1: 1$ series of dilutions of the peptides and the controls $(50 \mu \mathrm{L}$ peptide dilutions with $50 \mu \mathrm{L} \mathrm{O}+$ erythrocyte solutions) and haemolysis \% was calculated as recommended [13].

\section{The effect of antimicrobial peptides on $L .(V)$ panamensis and L. (L) major promastigote forms}

Pentamidine isethionate (Pentacarinat Rhone Poulenc Rorer, Dagenham, UK) and paromomycin sulphate (Paromomycin, PhytoTechonology Laboratories, Shawnee Mission, Kansas, USA) were used as control drugs having antileishmanial activity. The parasites were monitored by $L$. (V) panamensis promastigote morphology and motility at 5,24 and 72 hours exposure and their viability was evaluated following the methodology described in [22]. Rezorufin production was monitored as recommended [23] and the data was normalised for calculating the percentage of live parasites in the samples, as described in [24].

\section{Statistical analysis}

The normalised values were expressed as the arithmetic mean \pm standard deviation of the mean (95\% confidence limit), the $50 \%$ of inhibitory concentration (IC50) being calculated in $\mu \mathrm{g} / \mathrm{mL}$ and the $50 \%$ of effective concentration (EC50) in $\mu \mathrm{g} / \mathrm{mL}$ by a non-linear regression method in dose-response ratio using GraphPad Prism (version 5.0) demo software (GraphPad Software, Inc, the Jolla, CA, USA) [25]. Twoway analysis of variance (ANOVA test) was followed by Bonferroni post-test and establishing whether a significant difference could be found in treatment, bearing associated error in mind.

\section{Results}

Bioinfomatics and secondary structure elements in antimicrobial peptides

Blast analysis were performed to each peptide sequence in order to verify existance of homologous or orthologous genes coding for them in different species such as invertebrates, anphibians, fish, mammals, fungi, bacteria, virus and parasites including those belonging to the leismania genus amongst others. Also multiple alignments of peptide sequences by ClustalW were performed in order to examining possible identity and homology degrees. As a result most sequences do not share specific amino acid motifs responsible for their antimicrobial activity as well as structural differences at individual level between them became evident as further discussed and few of them have been previously

\begin{tabular}{|c|c|c|c|c|c|c|c|c|c|c|c|c|c|c|}
\hline \multirow[b]{2}{*}{ Analyte } & \multirow{2}{*}{\begin{tabular}{|l}
$\mathbf{J} 774$ \\
$\mathrm{IC}_{50}$ \\
$(\mu \mathrm{g} / \mathrm{mL})$
\end{tabular}} & \multirow{2}{*}{$\begin{array}{l}\text { Adherent } \\
\text { U937 } \\
\mathrm{IC}_{50} \\
(\mu \mathrm{g} / \mathrm{mL})\end{array}$} & \multirow{2}{*}{$\begin{array}{l}\begin{array}{l}\text { Non- } \\
\text { adherent } \\
\text { U937 }\end{array} \\
\mathrm{IC}_{50} \\
(\mu \mathrm{g} / \mathrm{mL})\end{array}$} & \multirow{2}{*}{$\begin{array}{l}\text { HPBM } \\
\mathrm{IC}_{50} \\
(\mu \mathrm{g} / \\
\mathrm{mL}) \\
\end{array}$} & \multirow{2}{*}{$\begin{array}{l}\text { L. }(\text { V.) } \\
\text { panamensis } \\
\mathrm{EC}_{50} \\
(\mu \mathrm{g} / \mathrm{mL})\end{array}$} & \multicolumn{2}{|l|}{$\begin{array}{l}L(L .) \\
\text { major }\end{array}$} & \multicolumn{3}{|c|}{$\begin{array}{l}\text { (V.) panamensis } \\
=\left(\mathrm{IC}_{50} / \mathrm{EC}_{50} \text { promastigotes }\right)\end{array}$} & \multicolumn{4}{|c|}{$\begin{array}{l}\text { L. (I.) major } \\
\mathrm{SI}=\left(\mathrm{IC}_{50} / \mathrm{EC}_{50} \text { promastigotes }\right)\end{array}$} \\
\hline & & & & & & $\begin{array}{l}\mathrm{EC}_{50} \\
(\mu \mathrm{g} / \\
\mathrm{mL})\end{array}$ & J774 & $\begin{array}{l}\text { Adherent } \\
\text { U937 e }\end{array}$ & $\begin{array}{l}\text { Non } \\
\text { adherent } \\
\text { U937 }\end{array}$ & HPBM & J774 & $\begin{array}{l}\text { Adherent } \\
\text { U937 }\end{array}$ & $\begin{array}{l}\text { Non- } \\
\text { adherent } \\
\text { U937 }\end{array}$ & HPBM \\
\hline Mangainin 1 & 25.3 & $>50.0$ & $>50.0$ & $>50.0$ & $>50.0$ & $>50.0$ & 0.5 & 1.0 & 1.0 & 1.0 & 0.5 & 1.0 & 1.0 & 1.0 \\
\hline $\begin{array}{l}\text { Dermaseptin } \\
\text { S1 }\end{array}$ & 36.7 & $>50.0$ & 46.3 & 49.9 & 24.6 & 25.4 & 1.5 & 2.0 & 1.9 & 2.0 & 1.4 & 2.0 & 1.8 & 2.0 \\
\hline Bombinin & 27.4 & $>50.0$ & 25.6 & 30.1 & 26.4 & $<6.3$ & 1.0 & 1.9 & 1.0 & 1.1 & 4.4 & 8.0 & 4.1 & 4.8 \\
\hline Andropin & $>50.0$ & $>50.0$ & $>50.0$ & $>50.0$ & $>50.0$ & $>50.0$ & 1.0 & 1.0 & 1.0 & 1.0 & 1.0 & 1.0 & 1.0 & 1.0 \\
\hline TAP & $>50.0$ & $>50.0$ & $>50.0$ & $>50.0$ & 46.3 & 23.2 & 1.1 & 1.1 & 1.1 & 1.1 & 2.2 & 2.2 & 2.2 & 2.2 \\
\hline Cecropin B & $>50.0$ & $>50.0$ & $>50.0$ & $>50.0$ & $>50.0$ & $>50.0$ & 1.0 & 1.0 & 1.0 & 1.0 & 1.0 & 1.0 & 1.0 & 1.0 \\
\hline Cecropin P1 & $>50.0$ & $>50.0$ & $>50.0$ & $>50.0$ & $>50.0$ & $>50.0$ & 1.0 & 1.0 & 1.0 & 1.0 & 1.0 & 1.0 & 1.0 & 1.0 \\
\hline Cecropin A & $>50.0$ & $>50.0$ & $>50.0$ & $>50.0$ & $>50.0$ & $>50.0$ & 1.0 & 1.0 & 1.0 & 1.0 & 1.0 & 1.0 & 1.0 & 1.0 \\
\hline Polystes MA & $>50.0$ & $>50.0$ & $>50.0$ & $>50.0$ & $>50.0$ & 40.7 & 1.0 & 1.0 & 1.0 & 1.0 & 1.2 & 1.2 & 1.2 & 1.2 \\
\hline Melittin & 43.8 & $>50.0$ & $>50.0$ & 22.3 & 7.6 & $<6.3$ & 5.8 & 6.6 & 6.6 & 2.9 & 7.0 & 8.0 & 8.0 & 3.6 \\
\hline Tachyplesin I & $>50.0$ & $>50.0$ & $>50.0$ & $>50.0$ & $>50.0$ & 42.1 & 1.0 & 1.0 & 1.0 & 1.0 & 1.2 & 1.2 & 1.2 & 1.2 \\
\hline Apamin & $>50.0$ & $>50.0$ & $>50.0$ & $>50.0$ & $>50.0$ & $>50.0$ & 1.0 & 1.0 & 1.0 & 1.0 & 1.0 & 1.0 & 1.0 & 1.0 \\
\hline Pr-2 & $>50.0$ & $>50.0$ & $>50.0$ & $>50.0$ & $>50.0$ & $>50.0$ & 1.0 & 1.0 & 1.0 & 1.0 & 1.0 & 1.0 & 1.0 & 1.0 \\
\hline MP-8 & 34.4 & $>50.0$ & 20.9 & 49.6 & 27.0 & 15.9 & 1.3 & 1.9 & 0.8 & 1.8 & 2.2 & 3.1 & 1.3 & 3.1 \\
\hline MP-17 & $>50.0$ & $>50.0$ & $>50.0$ & $>50.0$ & $>50.0$ & $>50.0$ & 1.0 & 1.0 & 1.0 & 1.0 & 1.0 & 1.0 & 1.0 & 1.0 \\
\hline MP-X & 35.4 & $>50.0$ & 25.1 & $>50.0$ & 49.9 & $>50.0$ & 0.7 & 1.0 & 0.5 & 1.0 & 0.7 & 1.0 & 0.5 & 1.0 \\
\hline $\begin{array}{l}\text { Pentamidin } \\
\text { isothionate }\end{array}$ & 8.5 & $>3.0$ & 20.5 & $<3.4$ & $<3.1$ & $<1.5$ & 2.7 & 16.1 & 6.6 & 1.1 & 5.7 & 33.3 & 13.7 & 2.3 \\
\hline $\begin{array}{l}\text { Paromomycin } \\
\text { sulphate }\end{array}$ & $>50.0$ & $>3.0$ & $>50.0$ & $>50.0$ & 22.8 & $<1.5$ & 2.2 & 2.2 & 2.2 & 2.2 & 33.3 & 33.3 & 33.3 & 33.3 \\
\hline CLIP & $>50.0$ & $>50.0$ & $>50.0$ & $>50.0$ & $>50.0$ & $>50.0$ & 1.0 & 1.0 & 1.0 & 1.0 & 1.0 & 1.0 & 1.0 & 1.0 \\
\hline
\end{tabular}

Table 2: The effect of antimicrobial peptides on cell viability. Promastigote forms of $L$. (V) panamensis and $L$. (L) major used for determining (IC50), (EC50) and selectivity index (SI) after 72 hours exposure to peptides. 


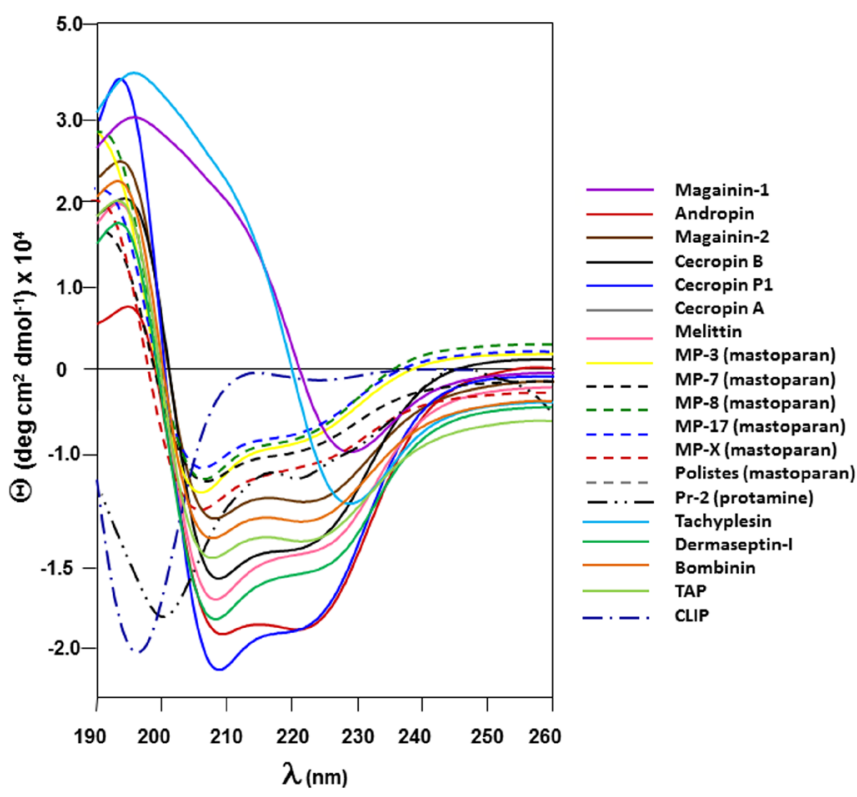

Figure 1: Secondary structure patterns for antimicrobial peptides. Circular Dichroism (CD) experiments were carried-out to analyse secondary profiles present in selected cationic antimicrobial peptides. Resulting patterns are expressed as mean residue ellipticity $(\theta)$, the units being degrees $\cdot \mathrm{cm}^{2} \cdot \mathrm{dmol}^{-1}$ according to the $(\theta)=\theta \lambda /(100 \mathrm{lcn})$ function where $\theta \lambda$ is the measured ellipticity, I the optical path length, $c$ the peptide concentration, and $\mathrm{n}$ is the number of amino acid residues in the sequence.

tested for its potencial antileismanial activity. However some peptide features can be extrapolated form these preliminary studies, most of them are amphipathic and cationic residues such as Lys, Arg and His, are frequently found in their primary structure as well as some small amino acid stretches constituted by non-polar residues such as Ala, Val, Leu and Gly seem to play an important role for their antimicrobial activity, and so Cys residues strategicaly located in some members of this peptide kingdom, led formation of domains key for peptidase resistance to degradation and so preserving their biological activity. In consequence, eighteen antimicrobial peptide sequences were selected for their assessment as potencial antileishmanial activity, and the human endogenous expressed peptide so-called CLIP, a non-relevant sequence was also included as the control.

All synthesised antimicrobial peptides and peptide controls were analysed by $\mathrm{CD}$ experiments. As observed in Figure 1 sixteenth peptides displayed strong structure patterns resembling $\alpha$-helix as the predominant secondary structure profile, amongst them the six-member mastoparan family, andropin, cecropins A, B and P1, magainin-2, melittin, dermaseptin S1, TAP and bombinin. On the other hand only two antimicrobial peptides displayed $\beta$-strand profiles, these were magainin-1 and tachyplesin, one displayed random structure fetarures ( $\mathrm{Pr}-2$, a protamine derivative) and a classical polyproline-II structure profile was evidenced by CLIP. All peptide CD profiles were deconvoluted for studying each structure element proportion (data not shown but available).

\section{The effect of antimicrobial peptides on nucleated eukaryotic cells and erythrocyte}

The antimicrobial peptides had a negative concentrationdependent relationship regarding viability in the cells evaluated here. Only magainin-1, dermaseptin-S1, bombinin, melittin, MP-8 and MP-X at maximum $50 \mu \mathrm{g} / \mathrm{mL}$ concentration $(\mathrm{p}>0.05)$ caused a reduction of more than $70 \%$ live cells (Figure $2 \mathrm{~A}$ ) in J774 cells at the concentrations used here $(6.25$ to $50 \mu \mathrm{g} / \mathrm{mL})$. These six peptides IC50 were close to $25 \mu \mathrm{g} / \mathrm{mL}$ compared to $8.5 \mu \mathrm{g} / \mathrm{mL}$ IC50 for pentamidine isethionate (Table 2)

Differences were observed between the peptides' effect on both U937 cell line phenotypes in such a way that whilst bombinin and melittin induced a slight loss of macrophage viability $(20 \%)$ at the maximum concentration used $(50 \mu \mathrm{g} / \mathrm{mL})$, bombinin, MP-8, MP-X and pentamidine isethionate inhibited monocyte growth by $50 \%$ at a lower concentration $(25 \mu \mathrm{g} / \mathrm{mL})$ (Figure $2 \mathrm{~B}$ and $2 \mathrm{C}$ ). Melittin was not evaluated in non-adherent U937 cells.

Melittin and bombinin reduced the viability of $50 \%$ of the human peripheral-blood monocyte (HPBM) population at $22.3 \mu \mathrm{g} /$ $\mathrm{mL}$ and $30.1 \mu \mathrm{g} / \mathrm{mL}$ concentration, respectively, and around $90 \%$ of the cells at $50 \mu \mathrm{g} / \mathrm{mL}$. On the other hand, MP-8, dermaseptin-S1, Pr-2 and TAP had their maximum effect on $50 \%$ of the population at concentrations around $50 \mu \mathrm{g} / \mathrm{mL}$ (Figure 2D); these cells, together with U937 monocytes, were the most sensitive cells to the selected peptides' action. Melittin was the only antimicrobial peptide (like pentamidine isethionate) which reduced the cell viability of around $60 \%$ of the population at $50 \mu \mathrm{g} / \mathrm{mL}$ maximum concentration.

HeLa and HepG2 cells were the most resistant to antimicrobial peptide action; it was observed that only melittin reduced the viability of $60 \%$ to $70 \%$ of the cell population at $50 \mu \mathrm{g} / \mathrm{mL}$ and, like all previously evaluated cells (J774, non-adherent U937 phenotype, HPBM and HeLa cells), melittin's effect on cell viability was less than that of pentamidine isethionate (Figure $2 \mathrm{~F}$ and $2 \mathrm{G}$ ).

Melittin lysed $96.8 \%$ of the erythrocytes at $12.5 \mu \mathrm{g} / \mathrm{mL}$, as previously described [26], having absorbance greater than that of distilled water ( $100 \%$ haemolysis as control). Other haemolytic peptides at maximum $50 \mu \mathrm{g} / \mathrm{mL}$ concentration were MP-X (52.1\%), dermaseptin-S1 (32.1\%), MP-8 (29.6\%), bombinin (17.4\%) and Polystes MA (14.9\%) (Figure $2 G)$.

\section{The influence of antimicrobial peptides on Leishmania panamensis and Leishmania major Promastigote form}

Melittin and pentamidine isethionate inhibited $98 \%$ and $100 \%$ of cell viability at 25 and $50 \mu \mathrm{g} / \mathrm{mL}$ concentrations, respectively, whilst MP-8, bombinin, dermaseptin-S1 and paromomycin sulphate only had an effect on $50 \%$ and $80 \%$ of the population at the same concentrations $(\mathrm{p}<0.05)$. Polystes MA, MP-X, TAP and Pr-2 had little activity at 50 $\mu \mathrm{g} / \mathrm{mL}$, only reducing $50 \%$ of the population. Magainin- 1 , andropin, cecropins A, B and P1, tachyplesin, apamin and MP-17 had no effect on promastigote viability following 72 hours incubation at the maximum concentration used $(50 \mu \mathrm{g} / \mathrm{mL})$ (Figure $3 \mathrm{~A})$.

It was observed that 13 of the antimicrobial peptides (76.5\%) reduced promastigote motility from $25 \%$ to $100 \%$ after five hours exposure at $50 \mu \mathrm{g} / \mathrm{mL}$ concentration, having no effect after 72 hours' incubation on parasites treated with cecropin P1, apamin and/or MP17 .

Only parasites exposed to TAP and cecropin A acquired a rounded form, no alterations to the rest of the 14 peptides occurring after five hours. Abundant cell debris was produced in the wells containing parasites treated with melittin, MP- 8 and MP-X and pentamidine isethionate at 24 hours and just at 72 hours in those exposed to Polystes MA, tachyplesin I and paromomycin sulphate. 

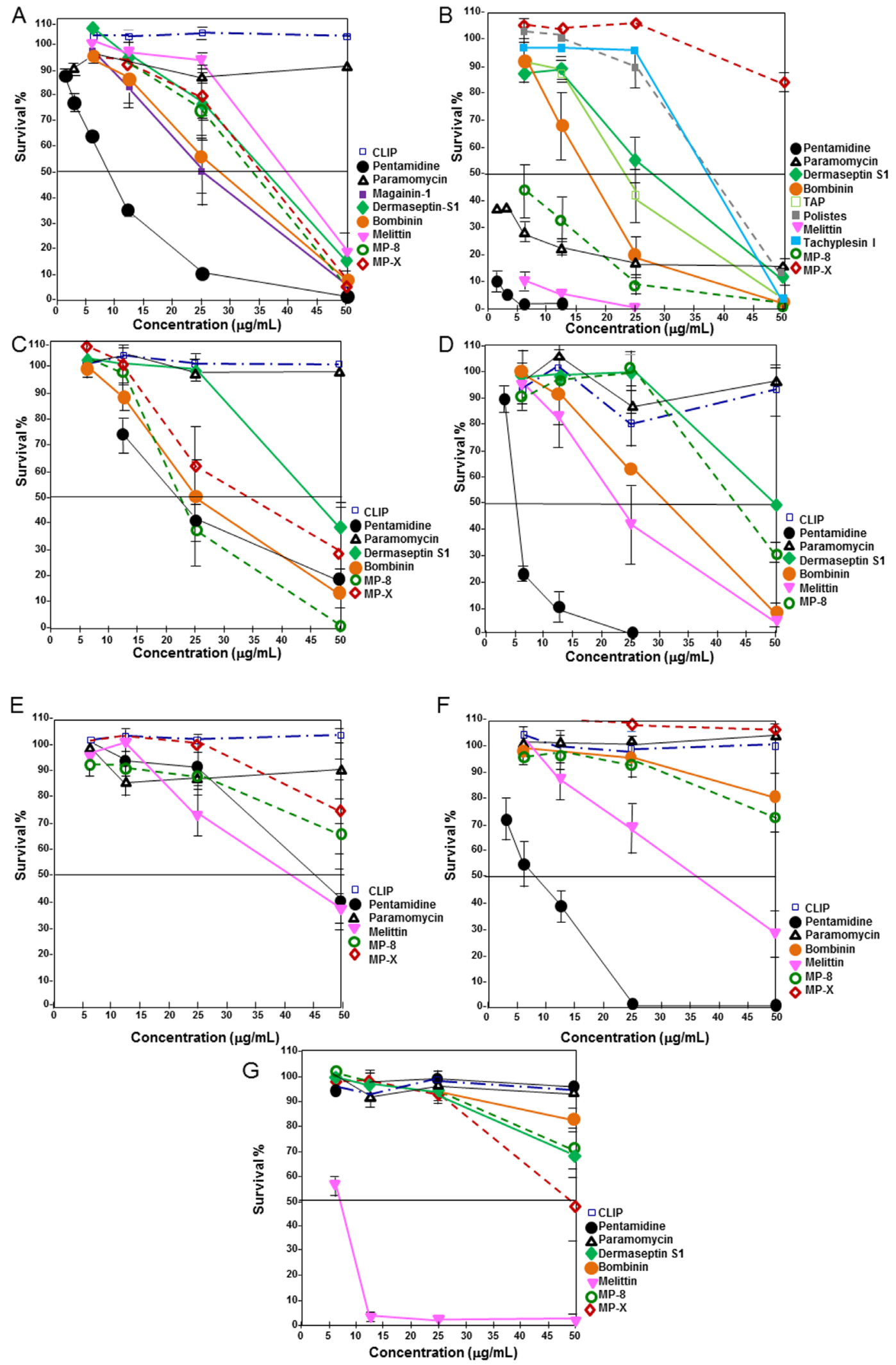

Figure 2: Antimicrobial peptides' effect on potential Leishmania parasite host cells, HeLa and HepG2 cells and O+ erythrocytes. A) J774, B) U937 adherent phenotype (macrophage), C) U937 non-adherent phenotype (monocyte) and D) human peripheral-blood monocytes (HPBM), E) HeLa cells, F) HepG2 cells and G) O+ erythrocytes. 
Antimicrobial peptides dermaseptin-S1, bombinin, melittin, tachyplesin I, MP-8 and MP-X caused a 100\% reduction of $L$. (V) panamensis promastigote motility at 72 hours, accompanied by apparent parasite destruction (debris), in turn reducing parasite viability in the assay with resazurin.

Melittin and pentamidine isethionate reduced $L$. (L) major promastigote viability for more than $90 \%$ of promastigotes at concentrations below 6.3 and $1.5 \mu \mathrm{g} / \mathrm{mL}$, respectively, followed by bombinin, MP-8 and paromomycin sulphate having an effect on $80 \%$ of the population at close to $25 \mu \mathrm{g} / \mathrm{mL}$ concentration ( $\mathrm{p}>0.05$ ). Other peptides having activity on this species were TAP, dermaseptin-S1, maganin- 1 and MP-X, but at greater concentrations (Figure 3B) (Table 2).

Thus, the most active antimicrobial peptides against $L .(V)$ panamensis promastigote forms were melittin, dermaseptin-S1, bombinin and MP-8, TAP, MP-X, Polystes MA and Pr-2 and melittin. Bombinin, MP-8, TAP and dermaseptin-S1 on $L$. (L) major, followed by tachyplesin I, Polystes MA, MP-X and magainin-1. Differences were identified regarding the sensitivity of these two parasite species in promastigote form to the action of TAP, bombinin, Polystes MA and paromomycin sulphate, $L$. $(L)$ major being sensitive to the action of the peptides (Table 2).

The selectivity index (SI) was obtained by dividing the IC50 of a substance in the host cell into the EC50 in promastigotes; if this were greater than one it would have indicated that a substance being evaluated was more selective on the promastigote form and if it were equal to or less than 1 it would have been more selective for the potential host cell, based on that fact that promastigotes are more resistant than amastigotes to the action of substances having antileishmanial activity [27]. Melittin, dermaseptin-S1, MP-8, bombinin and TAP were more selective (SI $>1)$ on $L$. (V) panamensis, whilst this was true for bombinin, melittin, MP-8, TAP, dermaseptin-S1, Polystes MA and tachyplesin I on L. (L) major (Table 2).

\section{Discussion}

As mentioned above, some features displayed by the analysed antimicrobial peptides became evident form this study. They do not share either a consensus secondary structure pattern, or a specific antimicrobial motif composed by given amino acid stretchs or a given peptide-length that can be associated to an active antimicrobial peptide. However some of these molecules are neither toxic nor haemolytic but dispaly amphipathic helices and cationic amino acid residues such as Lys, Arg and His, can be found in their primary structure as well as some small amino acid stretches constituted by non-polar residues such as Ala, Val, Leu combined with Gly seem to play an important role for their antimicrobial activity associated to their tridimenssional conformation which paradoxically can be randomly organised in some of these peptides, and finally some of them contain Cys residues strategicaly located led the formation of active domains as occurs in complex active polypeptides fond in nature.

As there is a direct correlation between resazurin reduction in culture medium and the proliferation/amount of live organisms in the resazurin reduction test [28], it was considered appropriate for evaluating antimicrobial peptides' effect on nucleated cells and parasites. Dermaseptin-S1, bombinin, melittin, MP-8 and MP-X reduced the cell viability of the four types of potential Leishmania host cells whilst only melittin had an effect on immortal HeLa cell line and HepG2 cells. The resistance shown by HeLa and HepG2 cells suggested that the peptides evaluated here (except for melittin) might not have any harmful effect on HeLa cells and hepatocytes, thereby favouring the desired topical use.

HPBM cells had the greatest variability of the four cell groups. The lot-by-lot differences of the cells having a Buffy coat obtained from the bags of donors' blood may have influenced the quality of the monocytes obtained and thus the results, especially the varity of cells from different individuals [29]. On the other hand, both types of response in U937 cells could be explained by a mechanism in which cells being free in culture have greater surface and longer contact time with different compounds, especially because all the medium consumed during the 72 hours' exposure cannot be removed (such action probably having taken place during the four hours required for rezorufin production). However, a potential protease effect cannot be discarded, particularly metalloproteases produced by activated U937 macrophages [30].

Natural peptides have a short half-life in the blood, possibly due to the presence of peptidases. It thus becomes indispensable that their protease resistance or sensitivity profile be evaluated (after studying promising peptides in in vitro and in vivo infection models in hamsters), especially when considering their future use in different formulations by different administration routes to the topical one and because Leishmania also produces proteases able to damage the peptides and thus inhibit their action.

Pentamidine isethionate was not haemolytic in spite of having a greater inhibitory effect regarding viability on most types of cell analysed here ( 4.0 to $20.5 \mu \mathrm{g} / \mathrm{mL}$ IC50) (Table 2). This led to considering haemolytic activity as a safety parameter when identifying promising peptides, as it was hoped that the erythrocytes would be less susceptible to rupture due to the presence of cholesterol on the membrane, such molecule stabilising the lipid bilayer and increasing resistance to antimicrobial peptide entry [31].

The fact that MP-8 and dermaseptin-S1, together with another 11 peptides, reduced $L$. (V) panamensis promastigote motility after 5 hours' incubation and did not produce substantial changes in morphology (rounded cells) led to considering possible action at membrane level due to the short time in which activity appeared and the peptides' secondary structure tendency to form an a-helix (Table 1).

Members of the subgenera Leishmania Viannia express lipophosphoglycan (LPG) levels from $5 \%$ to $10 \%$, as well as high levels of glycoinositol phospholipids in $L$. (V) panamensis and braziliensis parasite membranes have been reported [32]. As antimicrobial peptides have an affinity for phospholipids, then such lower LPG percentage

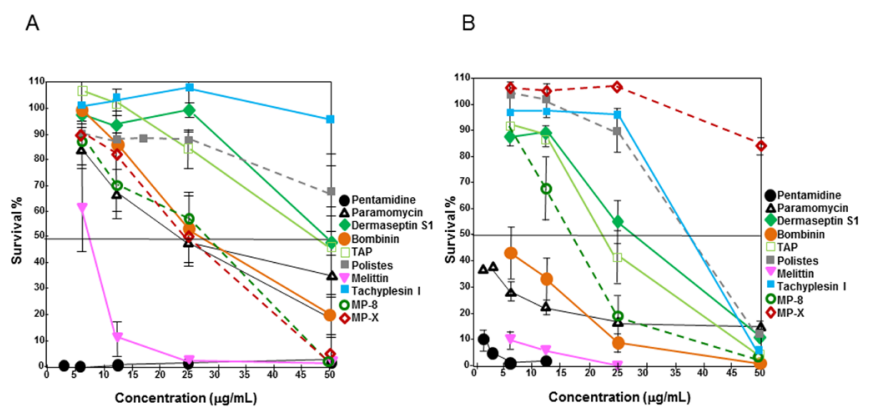

Figure 3: Antimicrobial peptides' effect on Leishmania promastigotes. A Leishmania Viannia panamensis and B. Leishmania Leishmania Major. 
at membrane level in the Viannia subgenera could give place to less interaction with the membrane and explain the difference in activity regarding $L .(V)$ panamensis and $L$. (L) major.

The Leishmania membrane has some particular characteristics. It has a strong negative charge due to the high levels of LPG anionic polysaccharide, covering more than $60 \%$ of the surface, it is associated with high proteolytic activity due to the presence of Gp63 (more than $5 \times 10^{5}$ copies/parasite) and its lipid composition is characterised by having a higher percentage of anionic phospholipids than standard mammal membranes ( $30 \%$ ergosterol in place of cholesterol). This contributed towards increasing membrane fluidity, thereby explaining melittin, MP-8, dermaseptin-S1, bombinin, TAP, Polystes MA and tachyplesin I selectivity regarding promastigotes (SI $>1)$.

Antimicrobial peptides were selected as promising if they were seen to be effective on Leishmania promastigotes $(\mathrm{SI}>1)$ and haemolysis percentage-inducing (safety criterion) at concentrations greater than that inhibiting human nucleated cell viability (Table 2). This led to MP8, bombinin, dermaseptin-S1 and TAP for both parasite species and tachyplesin I and Polystes MA being selected for $L$. (L) major; their effectiveness should continue to be evaluated through studies regarding the intracellular or amastigote form in an in vivo model in hamsters. Even though melittin had a high SI, its highly haemolytic and cytotoxic behaviour disqualified it from being considered as promising [26].

The EC50 found by other authors for tachyplesin I, dermaseptin-S1 and melittin regarding Leishmania promastigotes were similar to those reported in the present study $[8,9,13,14]$. Slight differences could have been due to species' membrane characteristics or the technique used for evaluating antileishmanial activity.

Andropin, cecropins A, B and P1, apamin, Pr-2 and MP-17 and MP-X were not very effective on the Leishmania promastigote form at the maximum concentrations used $(50 \mu \mathrm{g} / \mathrm{mL})$; however, their antileishmanial activity should not be disregarded as they may need intracellular mechanisms to become activated, as shown by andropin and Pr-2 not being effective on promastigotes but, conversely, being so on intracellular amastigotes in an infection model with dendritic cells [8].

As all antimicrobial peptides had been tested for their in vitro activity against two representative Leishmania species and their individual conformational profiles had been previously obtained by circular dichroism (CD) experiments [17], it was decided to analyse the most active ones by in silico molecular modelling. Coordinates and data for each peptide were thus downloaded from the Protein Data Bank (PDB) (http://www.rcsb.org/pdb/home/home.do) regarding bombinin (PBD code 2AP8), dermaseptin-S1 (PBD code 2DD6), mastoparan (PDB 1D7N) and tachyplesin (PDB 1WO0) 3D structure determined by NMR or X-ray crystallography and molecularly modelled. Molecular models were obtained using Accelrys Inc. Viewer Lite 4.2 software (www.accelrys.com).

Figure 4 shows the backbone disposition of bombinin (in A) and mastoparan (in B), both having high $\alpha$-helix content $(90 \%$ and $80 \%$, respectively), whilst dermaseptin-S1 had a small $\alpha$-helical stretch conserving high energy content $(\mathrm{C})$ and, remarkably, tachyplesin (D) was strongly $\beta$-stranded, facilitating antiparallel $\beta$-sheet features. Antileishmanial in vitro activity could provide amphipathic structural profiles present in these peptides related to their primary structure's high cationic and aliphatic amino-acid content, lysine, arginine and alanine being the most representative. As mentioned above, in spite of their high antimicrobial activity, strong differences at both structural and $3 \mathrm{D}$ conformation levels can be observed amongst all studied molecules.

It is well known that most mechanisms shown by antimicrobial peptides for being active against pathogen microbes depend on many aspects such as their capacity of stabilizing $\alpha$-helical conformations when in contact with negatively charged lipid bilayers, secondly this structure stabilisation can be the result of a voltage dissipation from the pathogen cell membrane, third, high hydrophobic environments would led specific peptide structures become better organized, that is the case of highly compact $\alpha$-helices in which a intra-catenary hydrogen bridge network allows amphipathic faces of the molecule to be properly organized. In consequence, carpet-shaped peptide agregates and pore formation will be the final step of mechanisms able to disrupt and destabilise the pathogens' outer membranes due to well organised peptide molecules and agregation so provoking cell damaging by the consequent uptake of bivalent cations and water to the cell cytosol. However, $\beta$-stranded and disulfide domains present on active peptides allow a sort of different antimicrobial mechanisms in which the peptide backbone integrity is crucial for interaction with the pathogen's membranes. Also, random conformations of a widerange of antimicrobial peptides such as protamine and its derivatives facilitate these molecules to adopt specific bioactive conformations able to a better interaction with pathogen's membranes and even these peptides high content of Arginine residues stimulate the peptide travel to the cell cytosol and crossing the nucleus membrane and so mechanisms directed towards interactions with DNA, will govern further pathogen destabilization and death. When thinking in novel antimicrobial peptides, independently of their secondary structure and amino acid composition, potent antimicrobial peptides would need to be neither toxic nor haemolytic, to posses high stability to peptidase and protease degradation and be formulated in suitable delivery systems to be used for topic or even parentally administratation in an infected subject to be trated. The next challenge will be consistent with site-directed modifications of selected antimicrobial peptides to afford a novel generation of antimicrobials, antitumoral, vaccine candidates
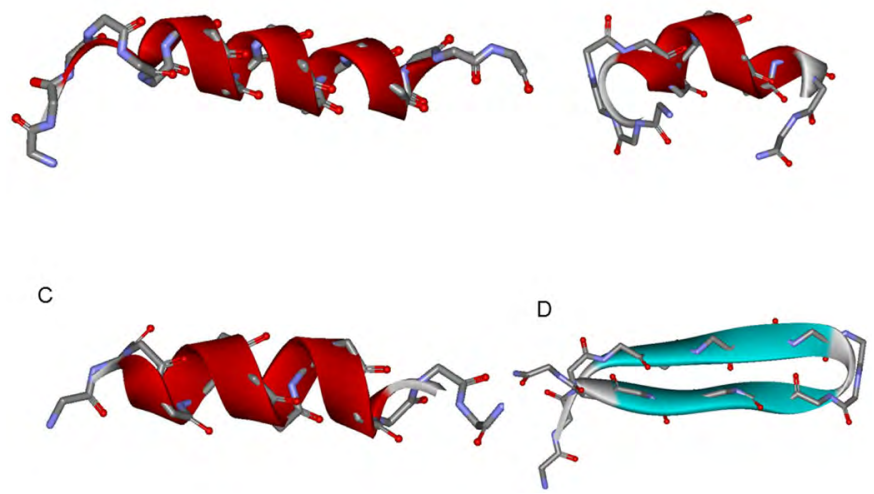

Figure 4: Conformational properties of antileishmanial active antimicrobia peptides. The most representative structures for peptide backbones were analyzed regarding their 3D structure. A) bombinin ( $\alpha$-helical of approximately 4.5 turns), B) dermaseptin S1 ( $\alpha$-helical of approximately 3 turns), C) mastoparan ( $\alpha$-helical of approximately 3.5 turns), and D) tachyplesin (antiparallel $\beta$-strand). Red ribbons represent $\alpha$-helixes and green arrows $\beta$-strands. Side-chain hydrogens were omitted in this analysis and peptide backbones are $\mathrm{N}$ to $\mathrm{C}$ orientated. 
Citation: Lozano JM, Cuadrado BS, Delgado LG, Patarroyo ME (2014) Cationic Peptides Harboring Antibiotic Capacity are Selective for Leishmania panamensis and Leishmania major. J Microb Biochem Technol 6: 054-062. doi:10.4172/1948-5948.1000122

and immunomodulating molecules. To revise latest advances in these interesting field some literature is recommended [33-36].

Taken together, the results presented herein demonstrate the potential use of these four molecules (or their modified versions) in appropriate formulations as possible antileishmanial agents. This should be explored further in in vivo assays thereby providing new insights as an alternative strategy for dealing with transmissible diseases in which causative pathogens are resistant to traditional antibiotics.

\section{Acknowledgements}

This research was financed by the Universidad Nacional de Colombia's Research Division Bogotá (DIB). L. (V) panamensis was kindly provided by D Martha Ayala from the Instituto Nacional de Salud (INS) (Bogotá, Colombia) and L. (L) major Friedlin 6 by Dr Manuel Soto from the Universidad Autónoma, Madrid (Spain). The HepG2 cells were kindly donated by Professor Fabio Aristizabal from the Universidad Nacional de Colombia's Cancer Immunogenetics Laboratory (Bogota, Colombia). Peptide synthesis and analytical characterization was performed in Chemistry Department of the Fundación Instituto de Inmunología de Colombia-FIFIC. We would like to thank Jason Garry for assistance provided in translation and grammar English style of the manuscript.

\section{References}

1. Desjeux P (2004) Leishmaniasis: current situation and new perspectives. Comp Immunol Microbiol Infect Dis 27: 305-318.

2. Murray HW, Berman JD, Davies CR, Saravia NG (2005) Advances in leishmaniasis. Lancet 366: 1561-1577.

3. World Health Organization (2013) Control of the Leishmaniases: Report of the meeting of the WHO expert committee on the control of Leishmaniases. WHO Technical report. Series 949 .

4. Mencia-Gutierrez E, Gutierrez-Diaz E, Rodriguez-Peralto JL, MonsalveCordova J (2005) Old World eyelid cutaneous leishmaniasis: a case report. Dermatol Online J 11: 29

5. Minodier P, Parola P (2007) Cutaneous leishmaniasis treatment. Travel Med Infect Dis 5: $150-158$

6. Brogden KA, Ackermann M, McCray Jr PB, Tack BF (2003) Antimicrobial peptides in animals and their role in host defences. Int $\mathrm{J}$ Antimicrob Agents 22: $465-478$.

7. Hancock RE, Diamond G (2000) The role of cationic antimicrobial peptides in innate host defences. Trends Microbiol 8: 402-410.

8. Perez-Cordero JJ, Lozano JM, Cortes J, Delgado G (2011) Leishmanicidal activity of synthetic antimicrobial peptides in an infection model with human dendritic cells. Peptides 32: 683-690.

9. Savoia D, Guerrini R, Marzola E, Salvadori S (2008) Synthesis and antimicrobial activity of dermaseptin S1 analogues. Bioorg Med Chem 16: 8205-8209.

10. Mangoni ML, Papo N, Saugar JM, Barra D, Shai Y, Simmaco M (2006) Effect of natural $\mathrm{L}$ - to $\mathrm{D}$-amino acid conversion on the organization, membrane binding, and biological function of the antimicrobial peptides bombinins $\mathrm{H}$. Biochemistry 45: 4266-4276

11. Lynn MA, Kindrachuk J. Marr AK, Jenssen H, Pante N, Elliott MR (2011) Effect of BMAP-28 antimicrobial peptides on Leishmania major promastigote and amastigote growth: role of leishmanolysin in parasite survival. PLoS Negl Trop Dis 5: e1141.

12. Mangoni ML, Saugar JM, Dellisanti M, Barra D, Simmaco M, Rivas L (2005) Temporins, small antimicrobial peptides with leishmanicidal activity. J Biol Chem 280:984-990.

13. Lofgren SE, Miletti LC, Steindel M, Bachere E, Barracco MA (2008) Trypanocidal and leishmanicidal activities of different antimicrobial peptides (AMPs) isolated from aquatic animals. Exp Parasitol 118: 197-202.

14. Guerrero E, Saugar JM, Matsuzaki K, Rivas L (2004) Role of positional hydrophobicity in the leishmanicidal activity of magainin 2. Antimicrob Agents Chemother 48: 2980-2986.
15. Merrifield RB (1964) Solid-Phase Peptide Synthesis. 3. An Improved Synthesis of Bradykinin. Biochemistry 3: 1385-1390.

16. Houghten RA, Ostresh JM, Pratt SM (1991) Modified solid-phase methods for the rapid synthesis of opioid peptides. NIDA Res Monogr 112: 239-255.

17. Lesmes LP, Bohorquez MY, Carreño LF, Patarroyo ME, Lozano JM (2009) A C-terminal cationic fragment derived from an arginine-rich peptide exhibits in vitro antibacterial and anti-plasmodial activities governed by its secondary structure properties. Peptides 30: 2150-2160.

18. Roccatano D, Colombo G, Fioroni M, Mark AE (2002) Mechanism by which 2,2,2-trifluoroethanol/water mixtures stabilize secondary-structure formation in peptides: a molecular dynamics study Proc Natl Acad Sci USA 99: 1217912184.

19. Chiu JH, Hu CP, Lui WY,Lo SC, Chang CM (1990) The formation of bile canaliculi in human hepatoma cell lines. Hepatology 11: 834-842.

20. Johnson WD, Mei B, Cohn ZA (1977) The separation, long-term cultivation, and maturation of the human monocyte. J Exp Med 146: 1613-1626.

21. Rasmussen ES (1999) Use of Fluorescent Redox Indicators to Evaluate Cell Proliferation and Viability. In vitro Mol Toxicol 12: 47-58.

22. Mikus J, Steverding D (2000) A simple colorimetric method to screen drug cytotoxicity against Leishmania using the dye Alamar Blue. Parasitol Int 48: 265-269.

23. de Oliveira-Silva F, de Morais-Teixeira E, Rabello A (2008) Antileishmanial activity of azithromycin against Leishmania (Leishmania) amazonensis, Leishmania (Viannia) braziliensis, and Leishmania (Leishmania) chagasi. Am J Trop Med Hyg 78: 745-749.

24. Salamanca-Capusiri E, Pinell GR, Huallpara JC, Turba AG (2008) Colorimetric method - XTT: as high-throughput screening of substances with leishmanicidal activity. Biofarbo 16: 21-27.

25. Botsford JL (2002) A comparison of ecotoxicological tests. Altern Lab Anim 30: $539-550$.

26. Tosteson MT, Holmes SJ, Razin M, Tosteson DC (1985) Melittin lysis of red cells. J Membr Biol 87:35-44.

27. Vermeersch M, da Luz RI, Tote K, Timmermans JP, Cos P, Maes L (2009) In vitro susceptibilities of Leishmania donovanipromastigote and amastigote stages to antileishmanial reference drugs: practical relevance of stage-specific differences. Antimicrob Agents Chemother 53: 3855-3859.

28. O'Brien J, Wilson I, Orton T, Pognan F (2000) Investigation of the Alamar Blue (resazurin) fluorescent dye for the assessment of mammalian cell cytotoxicity. Eur J Biochem 267: 5421-5426.

29. Draper G, Ramsey HJ, Dupertuis CW. (1944) Variation in behavior of buffy coat cultures among individuals of different constitution types J Clin Invest 23: 864-874.

30. Welgus HG, Campbell EJ, Cury JD, Eisen AZ, Senior RM, et al. (1990) Neutral metalloproteinases produced by human mononuclear phagocytes. Enzyme profile, regulation, and expression during cellular development. J Clin Invest 86: 1496-1502.

31. Shai $Y$ (1999) Mechanism of the binding, insertion and destabilization of phospholipid bilayer membranes by alpha-helical antimicrobial and cell nonselective membrane-lytic peptides. Biochim Biophys Acta 1462: 55-70.

32. dos Santos MG, Muxel SM, Zampieri RA, Pomorski TG, Floeter-Winter LM (2013) Transbilayer dynamics of phospholipids in the plasma membrane of the Leishmania genus. PLoS One. 8(1):e55604. doi: 10.1371/journal pone. 0055604

33. Guilhelmelli F, Vilela N, Albuquerque P, Derengowski LD, Silva-Pereira I, et al (2013) Antibiotic development challenges: the various mechanisms of action of antimicrobial peptides and of bacterial resistance. Front Microbiol 4: 353.

34. Bahar AA, Ren D (2013) Antimicrobial peptides. Pharmaceuticals (Basel) 6:1543-1575.

35. Park K, Lee S, Lee YM (2013) Sphingolipids and Antimicrobial Peptides: Function and Roles in Atopic Dermatitis. Biomol Ther (Seoul) 21: 251-257.

36. Sobczak M, Debek C, Oledzka E, Kozłowski R (2013) Polymeric systems of antimicrobial peptides--strategies and potential applications. Molecules 18(11): 14122-14137. 